\title{
Stage I Uterine Corpus Cancer AJCC v7
}

National Cancer Institute

\section{Source}

National Cancer Institute. Stage I Uterine Corpus Cancer A/CC v7. NCI Thesaurus. Code C89633.

Stage I includes: I (T1, N0, M0); IA: (T1a, N0, M0); IB (T 1b, N0, M0). T1: Tumor confined to corpus uteri. T1a: T umor limited to the endometrium or invades less than one-half of the myometrium. T1b: Tumor invades one-half or more of the myometrium. N0: No regional lymph node metastasis. M0: No distant metastasis. This staging applies to carcinomas and carcinosarcomas. (AJCC 7th ed.) 